\title{
Charting the Pacific ca. 1850: Melville, Maury, Marx, and Mormons [Video]
}

\author{
John Durham Peters ${ }^{a}$ \\ Keywords: synchronization, melville, maury, media, pacific \\ https://doi.org/10.1525/001c.22195
}

\begin{abstract}
Navigating different media such as maps, names, novels, or data charts, media philosophy complicates the question of how oceans become objects or things. And the Pacific's ontology appears to be particularly slippery: Around 1850, Herman Melville thinks of the Pacific through metaphysical or literary depictions, while Matthew Maury, one of the pioneers of oceanography, conceives of it as a data composite. Karl Marx understands it in terms of spacetime compression, and Mormon missionaries reimagine the Pacific theologically as a deep history. Yet, when read alongside each other, one can discover a media theory in oceanography, and an oceanography in literature, and there never seems to be enough time and space to tell the whole story of the Pacific.
\end{abstract}

Video available at: https://vimeo.com/527398349

\footnotetext{
a John Durham Peters is María Rosa Menocal Professor of English and Professor of Film and Media Studies at Yale and is the author of Speaking into the Air: A History of the Idea of Communication (1999), Courting the Abyss: Free Speech and Liberal Tradition (2005), The Marvelous Clouds: Toward a Philosophy of Elemental Media (2015), and Promiscuous Knowledge: Information, Image, and Other Truth Games in History (2020), co-authored with the late Kenneth Cmiel (all from the University of Chicago Press). He has advised or co-advised over three dozen doctoral dissertations, whose authors have all received academic positions. He has held extended visiting fellowships in England, Finland, Germany, Greece, the Netherlands, and Norway.
} 


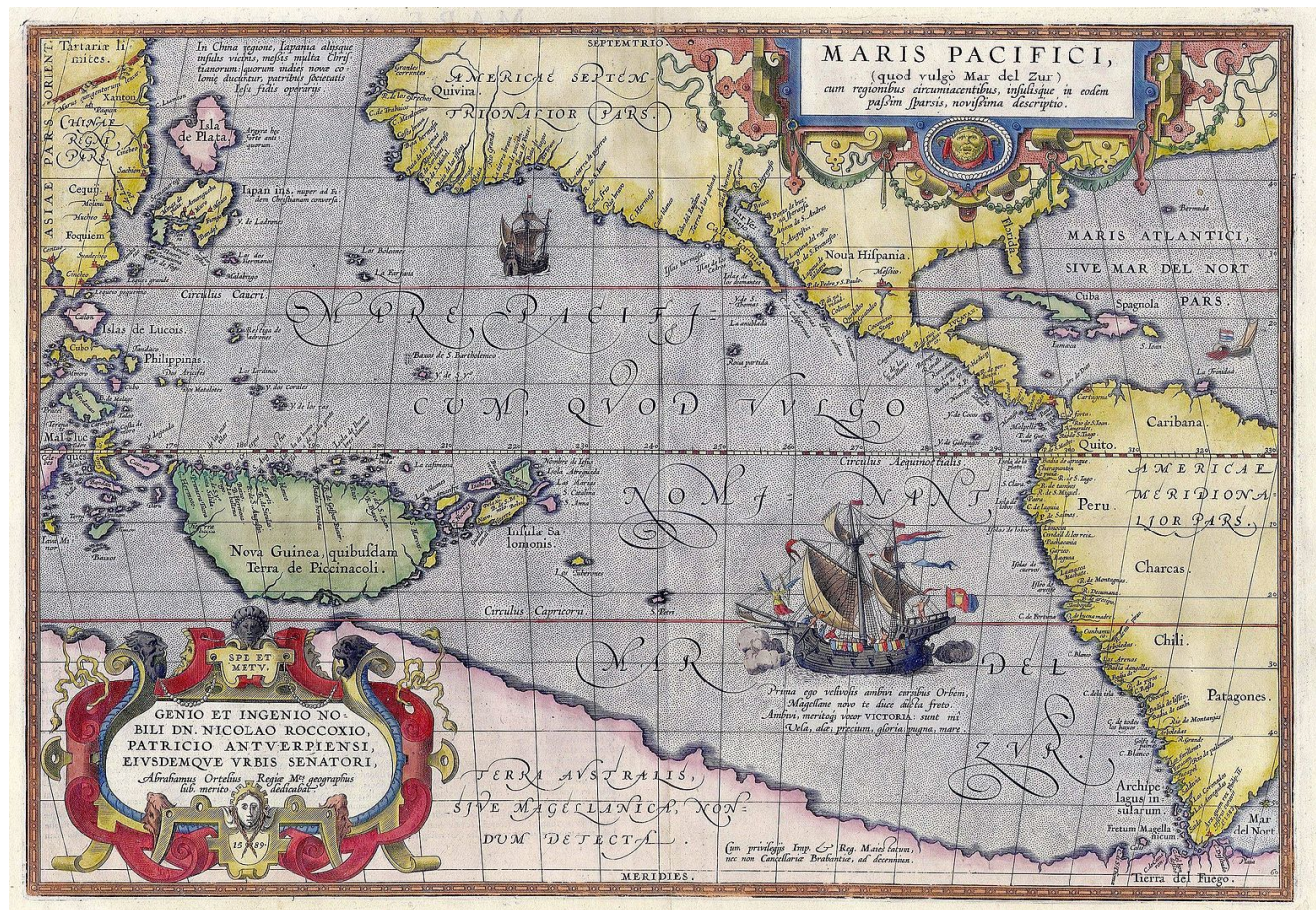

Figure 1: Descriptio Maris Pacific

Descriptio Maris Pacific was the first dedicated map of the Pacific to be printed (public domain, https://commons.wikimedia.org/w/ index.php?curid=2061644). 